\title{
Foscarnet Sodium
}

National Cancer Institute

\section{Source}

National Cancer Institute. Foscarnet Sodium. NCI Thesaurus. Code C1193.

The trisodium salt of a synthetic organic analogue of inorg anic pyrophosphate with antiviral activity. Foscarnet selectively blocks the pyrophosphate binding site of herpesvirus-specific DNA polymerases at concentrations that do not affect cellular DNA polymerases. This agent does not require phosphorylation by thymidine kinase (TK) or other kinases and therefore is active in vitro against herpes simplex virus (HSV) TK deficient mutants and cytomegalovirus (CMV) UL97 mutants. Because foscarnet crosses the blood brain barrier, it may be used in the treatment of viral infections of the CNS. 